\title{
Produção de sucedâneo da gordura do leite humano por interesterificação enzimática: uma revisão
}

\author{
Production of human millk fat substitute by enzyme interesterification: a review \\ Producción de sustituto de grasa de la leche humana mediante interesterificación enzimática: una \\ revisión
}

Recebido: 02/03/2021 | Revisado: 07/03/2021 | Aceito: 11/03/2021 | Publicado: 19/03/2021

\author{
Giovanna Caputo Almeida Ferreira \\ ORCID: https://orcid.org/0000-0001-5757-5962 \\ Universidade Estadual de Maringá, Brasil \\ E-mail: gicaputo@gmail.com \\ Jiuliane Martins da Silva \\ ORCID: https://orcid.org/0000-0003-4275-2019 \\ Universidade Estadual de Maringá, Brasil \\ E-mail: juli_ane.martins@hotmail.com \\ Geovane Aparecido Ramos da Silva \\ ORCID: https://orcid.org/0000-0003-3749-6938 \\ Universidade Estadual de Maringá, Brasil \\ E-mail: geovane.rsilva21@gmail.com \\ Isadora Boaventura Ponhozi \\ ORCID: https://orcid.org/0000-0001-7230-161X \\ Universidade Estadual de Maringá, Brasil \\ E-mail: isa.ponhozi@gmail.com \\ Matheus Campos de Castro \\ ORCID: https://orcid.org/0000-0002-9918-1491 \\ Universidade Estadual de Maringá, Brasil \\ E-mail: 1996mcastro@gmail.com \\ Patrícia Magalhães de Souza \\ ORCID: https://orcid.org/0000-0001-5916-0744 \\ Universidade Estadual de Maringá, Brasil \\ E-mail:patricia.magalhaes11@hotmail.com \\ Victor Hugo Maldonado da Cruz \\ ORCID: https://orcid.org/0000-0003-2050-9149 \\ Universidade Estadual de Maringá, Brasil \\ E-mail: victor.hugo.maldonado.cruz@gmail.com \\ Oscar de Oliveira Santos Junior \\ ORCID: https://orcid.org/0000-0002-9631-8480 \\ Universidade Estadual de Maringá, Brasil \\ E-mail: oliveirasantos.oscardeoliveira@gmail.com
}

\begin{abstract}
Resumo
O leite humano é considerado a principal fonte de nutrientes e energia para os bebês sob o ponto de vista nutricional, imunológico e de segurança alimentar. A melhor forma de assegurar a oferta dos nutrientes necessários para o lactente é por meio do leite materno, porém, quando a prática da amamentação é impossibilitada, o uso de Fórmula Infantil aparece como uma alternativa para a alimentação do bebê. O processo de Interesterificação de misturas entre gorduras sólidas e óleos vegetais pode formar produtos com excelentes características chamados lipídeos estruturados, que podem ser utilizados como sucedâneos da gordura do leite humano em fórmulas infantis. A Interesterificação enzimática oferece a vantagem de um maior controle sobre a distribuição posicional dos ácidos graxos no produto final, devido à seletividade e regioespecificidade das lipases nos ácidos graxos. Este trabalho reuniu trabalhos recentes sobre a produção de sucedâneo da gordura do leite humano por Interesterificação enzimática. Através da busca de referências pode-se notar que vários grupos de pesquisadores no mundo trabalham com testes de aprimoramento e ajuste da técnica de interesterificação e do uso da melhor enzima para a produção do sucedâneo a partir de diversas fontes naturais de óleos e gorduras. Porém ainda não há muitos registros de produtos patenteados. Dessa maneira faz-se necessário que mais pesquisas sejam desenvolvidas para que se chegue em um produto sucedâneo com as melhores característcas para que seja submetido a patente.
\end{abstract}

Palavras-chave: Lipídeo estruturado; Fórmula infantil; Triacilgliceróis (TAG).

\section{Abstract}

Human milk is considered the main source of nutrients and energy for babies from a nutritional, immunological, and 
food security point of view. The best way to ensure the supply of the necessary nutrients for the infant is through breast milk, however, when the practice of breastfeeding is impossible, the use of Infant Formula appears as an alternative for the baby's feeding. The Interesterification process of mixtures between solid fats and vegetable oils can form products with excellent characteristics called structured lipids, which can be used as substitutes for human milk fat in infant formulas. The interesterification enzymatic offers the advantage of greater control over the positional distribution of fatty acids in the final product, due to the selectivity and regiospecificity of lipases in fatty acids. This work brought together recent work on the fat substitute for the production of human milk by interesterification enzyme. Through the search for references, it can be noted that several groups of researchers in the world work with tests to improve and adjust the interesterification technique and the use of the best enzyme for the production of substitutes from different natural sources of oils and fats. However, there are still not many registrations of patented products. In this way, more research must be developed to arrive at a substitute product with the best characteristics for it to be submitted for a patent.

Keywords: Structured lipid; Infant formula; Triacylglycerols (TAG).

\section{Resumen}

La leche materna se considera la principal fuente de nutrientes y energía para los bebés desde el punto de vista nutricional, inmunológico y de seguridad alimentaria. La mejor forma de asegurar el aporte de los nutrientes necesarios para el lactante es a través de la leche materna, sin embargo, cuando la práctica de la lactancia materna es imposible, el uso de Fórmula Infantil aparece como una alternativa para la alimentación del bebé. El proceso de interesterificación de mezclas entre grasas sólidas y aceites vegetales puede formar productos con excelentes características denominados lípidos estructurados, que pueden utilizarse como sustitutos de la grasa de la leche materna en fórmulas infantiles. La interesterificación enzimática ofrece la ventaja de un mayor control sobre la distribución posicional de los ácidos grasos en el producto final, debido a la selectividad y regioespecificidad de las lipasas en los ácidos grasos. Este trabajo reunió trabajos recientes sobre el sustituto de grasas para la producción de leche materna por enzima de interesterificación. A través de la búsqueda de referencias, se puede notar que varios grupos de investigadores en el mundo trabajan con pruebas para mejorar y ajustar la técnica de interesterificación y el uso de la mejor enzima para la producción de sustitutos a partir de diferentes fuentes naturales de aceites y grasas. Sin embargo, todavía no hay muchos registros de productos patentados. De esta manera, se deben desarrollar más investigaciones para llegar a un producto sustituto con las mejores características para que sea presentado a una patente.

Palabras clave: Lípido estructurado; Formula infantil; Triacilgliceroles (TAG).

\section{Introdução}

O leite humano é considerado a principal fonte de nutrientes e energia para os bebês sob o ponto de vista nutricional, imunológico e de segurança alimentar (Bryś et al., 2017). É um alimento rico em gordura, minerais, vitaminas, enzimas e imunoglobulinas que protegem contra doenças. Apesar de o leite maduro ser formado por cerca de $87 \%$ de água, o restante, $13 \%$, é uma poderosa combinação de elementos fundamentais para o crescimento e desenvolvimento da criança (Silva \& Gioielli, 2009).

A fração lipídica é a principal fonte de energia para o neonato; contribuindo com $40 \%$ a $55 \%$ do total de energia consumida por ele em aleitamento materno exclusivo. Ela apresenta um conteúdo médio de 4,2g/dL, sendo constituída $98 \%$ por triacilgliceróis (TAG). Além de prover ao recém-nascido ácidos graxos essenciais, como o ácido linoleico (C18:2n-6) e ácido $\alpha$ linolênico (C18:3n-3), também oferece o Ácido Araquidônico (AA) (C20:4n-6), o Ácido Eicosapentaenoico (EPA) (C20:5n-3) e o Ácido Docosa-Hexaenoico - DHA (C22:6n-3), que não são sintetizados pelos recém-nascidos (Costa \& Sabarense, 2010).

Os lipídios são os constituintes mais variáveis do leite humano, e seu conteúdo e composição são influenciados por vários fatores, como período de lactação, dieta e diferenças individuais. Algumas características da gordura do leite humano são significativamente diferentes de outros lipídios naturais (Wei, Jin \& Wang, 2019).

Recentemente, a estrutura do TAG obteve mais atenção no que diz respeito à importância nutricional na digestão e metabolismo de lipídios. A distribuição de ácido palmítico (PA, 16:0) em TAGs de leite humano, por exemplo, é diferente em comparação com óleos vegetais e outras gorduras do leite de mamíferos. Cerca de 60-70\% de PA está localizado na posição sn2 dos TAGs de leite humano e os ácidos graxos insaturados e ácidos graxos poliinsaturados (PUFAs) estão nas posições sn-1 e 
sn-3; essas posiçães são importantes pois estão envolvidas na promoção da absorção de íons de cálcio além de evitar constipação dos bebês (He et al., 2017; Wang et al., 2016, Wei et al., 2015; Soumanou; Pérignon \& Villeneuve, 2013).

Além disso os ácidos graxos de cadeia média e os monoacilgliceróis possuem atividade antibacteriana, que pode ter efeitos funcionais no estabelecimento da microbiota intestinal e na função imune associada ao intestino no início da vida (Yuan et al., 2019; Nejrup, Licht, \& Hellgren, 2017).

A melhor forma de assegurar a oferta dos nutrientes necessários para o lactente é por meio do leite materno, porém, quando a prática da amamentação é impossibilitada, o uso de Fórmula Infantil aparece como uma alternativa para a alimentação do bebê. Apesar do avanço no processo tecnológico, essas fórmulas ainda apresentam grandes diferenças na composição quando comparadas ao leite materno e são principalmente constituídas de leite de vaca e óleos vegetais (Kus et al., 2011).

Segundo Wei, Jin \& Wang (2019), a distribuição posicional de três ácidos graxos principais na gordura do leite humano difere significativamente da gordura do leite de vaca e dos óleos vegetais típicos. A gordura do leite de vaca tem conteúdo semelhante de PA à gordura do leite humano, enquanto a porcentagem de PA ligada à posição sn -2 na gordura do leite de vaca (cerca de 40\%) e na gordura do leite humano (70\%) são diferentes. Em TAGs de óleos vegetais, ácidos graxos insaturados (como ácido oléico - OA e ácido linoléico - LA) são principalmente esterificados na posição sn -2, enquanto os ácidos graxos saturados como PA, estão ligados à posição sn -1,3, que está em contraste com a posição na gordura do leite humano.

Segundo Silva \& Gioielli, (2006), a Interesterificação de misturas entre gorduras sólidas e óleos vegetais pode formar produtos com excelentes características, o rearranjo ou a randomização dos ácidos graxos nos triacilgliceróis produz gorduras ou óleos com diferentes propriedades físicas chamados lipídeos estruturados (SL).

Os SLs são TAGs que foram quimicamente ou enzimaticamente modificados para alterar os ácidos graxos ligados à estrutura do glicerol, a fim de imitar a estrutura TAG (produzir um sucedâneo) da gordura do leite humano para uso em fórmula infantil (Yuan et al., 2020).

O Palmitato sn-2 é um típico triacilglicerol estruturado específico que pode ser sintetizado química e enzimaticamente. A síntese química produz produtos randomizados nos quais os ácidos graxos são distribuídos aleatoriamente entre as três posições da estrutura do glicerol. Contudo, algumas lipases, método enzimático, têm regioespecificidade sn-1,3 quando usado com alguns solventes orgânicos, que podem ser usados para modificar o ácido graxo na posição sn-1,3 (Forsyth, Gautier, \& Salem, 2017).

A Interesterificação enzimática oferece a vantagem de um maior controle sobre a distribuição posicional dos ácidos graxos no produto final, devido à seletividade e regioespecificidade das lipases nos ácidos graxos (Silva et al., 2012). Desse modo o objetivo deste trabalho foi fazer um levantamento de dados recentes sobre a produção de sucedâneos da gordura do leite humano pelo processo de Interesterificação enzimática.

\section{Metodologia}

O levantamento bibliográfico ocorreu entre outubro de 2020 e fevereiro de 2021 e a metodologia desta pesquisa foi apoiada pelos estudos de Pereira et al., (2018) e caracterizada de forma quantitativa avaliando os artigos científicos referentes a produção de sucedâneos da gordura do leite humano pelo processo de Interesterificação enzimática.

O levantamento bibliográfico se deu utilizando as palavras-chave: Interesterificação enzimática e leite humano e posteriormente a inclusão do termo lipídeos estruturados. Os termos foram pesquisados de forma conjunta para otimizar a busca de artigos de interesse.

Os artigos científicos foram pesquisados nos Periódicos Capes, Science Direct, Scielo (Scientific Electronic Library Online) e Pubmed com refinamento para o período de 2015 a 2021e selecionando somente artigo científico. Foi realizada uma plotagem gráfica utilizando Excel®, dos artigos encontrados por ano de publicação e posteriormente foram selecionadas as publicações que atendessem o objetivo do trabalho para discussão. 
Apesar da limitação do período outros artigos referência no assunto foram selecionados para compor a introdução e discussão deste trabalho independente da data da publicação.

\section{Resultados e Discussão}

A busca na plataforma Scielo com as palavras chave Interesterificação enzimática e leite humano, tanto em português, quanto em inglês, não obteve êxito resultando em nenhum artigo encontrado utilizando os dois termos de forma conjunta. A base Pubmed revelou uma quantidade menor de artigos comparado ao Portal Capes e Science Direct. Principalmente quando delimitou-se o período da publicação, com um total de 2 (dois) artigos encontrados para os termos pesquisados. Desse modo foi utilizado como base de dados, o Portal Capes e Science Direct para seleção dos artigos para discussão do trabalho.

A busca pelo Portal Capes resultou em 124 artigos publicados no período de 2015 à 2021. Pelo Science Direct o resultado foi de 91 artigos na pesquisa com as palavras Interesterificação enzimática e leite humano e limitado ao mesmo período. (Figura 1).

Figura 1 - Gráfico do número de artigos encontrados entre 2015 e 2021 nas buscas no Portal Capes e Science Direct.

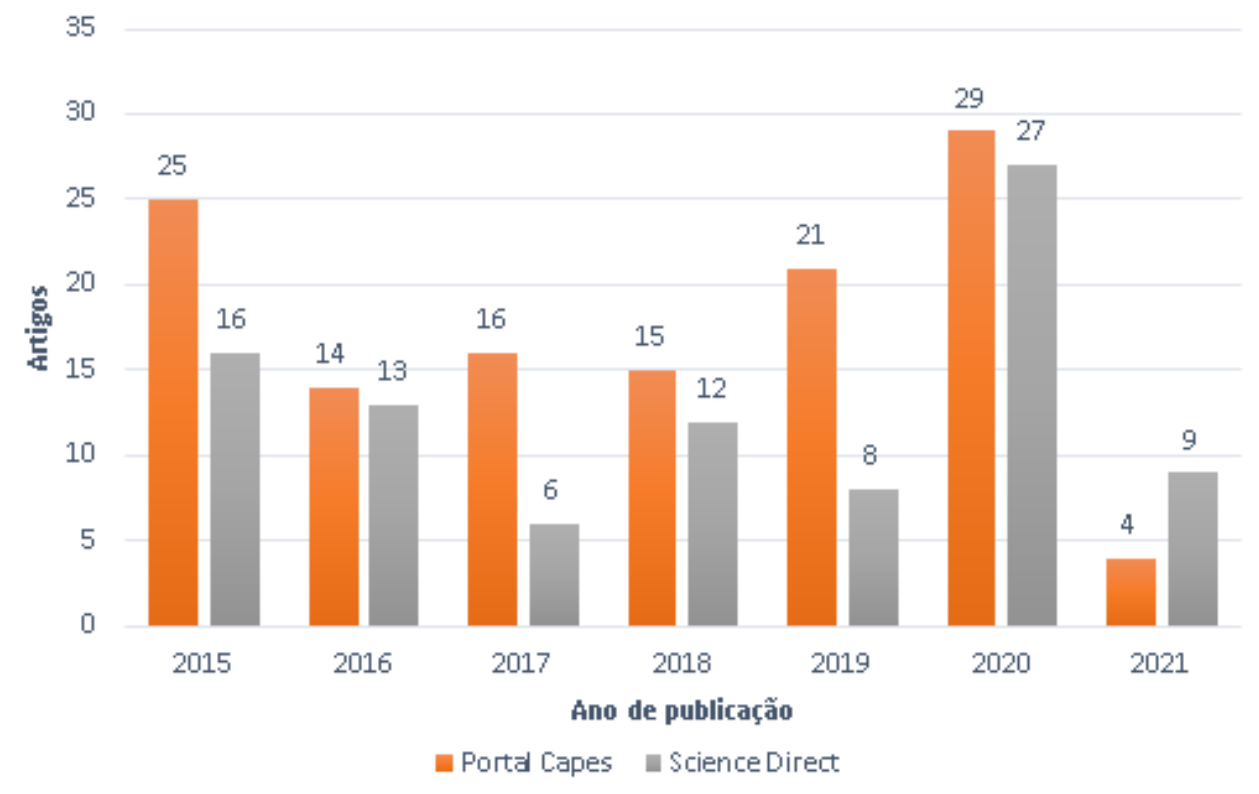

Fonte: Dados do Pesquisador.

A grande maioria dos trabalhos encontrados no Science Direct também foram encontrados no Portal Capes com destaque de exceção para dois trabalhos selecionados no Science Direct, Korma et al., (2018) e Wei, Jin e Wang, (2019) que não foram encontrados pela busca dos mesmos termos no Portal Capes.

Korma et al., (2018) fizeram um trabalho de pesquisa na qual sintetizaram SLs ricos em TAGs de cadeia média-longa (MLCTs), em um sistema livre de solvente utilizando quatro lipases imobilizadas comerciais de diferentes fontes para comparação quanto à sua eficiência.

TAGs de cadeia longa (LCTs) são a forma predominante de óleos comestíveis comuns e servem como fonte de ácidos graxos de cadeia longa (LCFAs), incluindo ácidos graxos essenciais (EFAs). Os TAGs de cadeia média (MCTs) têm o problema de deficiência de EFA, isso criou a necessidade de desenvolvimento de SLs específicos, chamados MLCTs, que retêm os benefícios tanto dos LCTs quanto dos MCTs, (Akoh \& Kim 2008). 
Os resultados revelados por Korma et al., (2018) indicaram que o maior rendimento de MLCTs foi alcançado pelo Lipozyme 435 como biocatalisador. Nas melhores condições de reação os SLs ricos em MLCTs obtidos podem ser sugeridos como um análogo nutricional e funcional da gordura com aplicações potenciais na indústria de fórmulas infantis.

O trabalho de Wei, Jin e Wang, (2019) é uma revisão na qual discutem a história e os avanços recentes em substitutos da gordura do leite humano (HMFSs). Eles relatam os esquemas de reação catalisada por enzimas e seus produtos dando destaque aos que já estão no mercado. O Betapolß desenvolvido por IOI Loders Croklaan (Channahon, IL, EUA) foi o primeiro sn -2 palmitato comercial. O produto foi sintetizado por um processo de uma etapa, pela acidólise da estearina de palma com OA (obtidos do óleo de girassol alto oleico), usando lipase imobilizada- sn1,3 regiosseletiva (Rhizomисor miehei) resultando em 65\% de PA na posição sn-2. Além do Betapolß também existem outros produtos de palmitato sn -2 comercializados, incluindo InFat ${ }^{\circledR}$ (AAK, Edison, NJ, EUA), Bonamil (Wyeth Ayerst), Also (Nestlé) e Cow e Gate Premium (Nutricia).

Kim \& Akoh (2015) também publicaram uma revisão bibliográfica com o intuito de fornecer informações concisas sobre as tendências recentes de pesquisa sobre a síntese enzimática de SLs de interesse comercial na indústria de alimentos usando lipases e fosfolipases como biocatalisadores.

Além dos trabalhos destacados do Science Direct relatados acima, dos 124 artigos encontrados pelo portal Capes, somente nove continham os dois termos buscados na íntegra, ou seja, realmente abordaram no trabalho Interesterificação enzimática e leite humano. Como os termos utilizados para a pesquisa eram compostos, a busca trouxe muitos trabalhos que abordavam parte dos termos como "enzimática" e "leite" ou "Interesterificação" e "humano" por exemplo; consequentemente não serviram para discussão no trabalho.

Dos nove trabalhos específicos encontrados, seis apresentaram como objetivo a produção de um substituto da gordura do leite humano (HFMS) por processo de interesterificação enzimática a partir de diversas fontes de óleos e gorduras naturais (Yuan et al., 2020; Tecelão et al., 2019; Ghosh et al., 2016; Zou et al., 2016; Djajasoepena et al., 2015; Lee et al., 2015).

Yuan et al., (2020), por exemplo sintetizaram Lípidos estruturados enriquecidos com TAGs de cadeia média e longa (MLCTs) por interesterificação de óleo de côco e de Bagre, usando a enzima NS 40086. O SL enriquecido com MLCT mostrou grande potencial de aplicação para o desenvolvimento de fórmulas infantis tornando sua composição TAG mais próxima da gordura do leite humano.

Ghosh et al., (2016), fizeram a interesterificação com estearina de palma fracionada (PSF) e óleo de peixe (FO) rico em ácidos graxos n-3 poliinsaturados (n-3 PUFA) catalisada pela lipase de Thermomyces lanuginosa para a obtenção de um produto com estrutura de TAG semelhante à da gordura do leite humano. A mistura de PSF e FO na razão molar de 2: 1 com teor de PA de $69,70 \%$ e 12 h de reação produziu o produto desejado com 75,98\% de PA em sn-Posição 2, 0,27\% de AA, 3,43\% de EPA e $4,25 \%$ de DHA e com ponto de fusão de $42{ }^{\circ}$ C. Este estudo retratou uma preparação bem-sucedida de TAG contendo composição única de FA, ou seja, $\geq 70 \%$ do PA, por peso, foram esterificados na posição $s n$ - 2 , que poderia ser usada em formulação infantil com benefícios para a saúde de n-3 PUFAs.

Tecelão et al., (2019), utilizaram a lipase / aciltransferase de Candida parapsilosis (CpLIP2) não comercial imobilizada em Accurel MP1000, como biocatalisador para a interesterificação de tripalmitina com oleato de etila em meio livre de solvente, para obtenção de lipídios estruturados usado como HMFS. A quantidade de ácido oleico na posição sn-2 foi de aproximadamente $15 \%$ para todas as razões molares testadas. CpLIP2 exibiu maior atividade do que a maioria lipases imobilizadas comerciais (por exemplo, reação mais rápida em meio sem solvente, baixa carga de enzima e baixa razão molar necessária),

e mostrou um comportamento regiosseletivo sn-1,3 reconhecido.

Lee et al., (2015), produziram os HFMS usando gorduras naturais não pré-processadas e óleos com lipase. Após interesterificação de tripalmitina e ácido oleico em isooctano, os produtos da reação continham 55,2\% de 1,3-dioleoil-2-palmitoil 
glicerol (OPO). O rendimento de OPO foi de 25,2\% quando óleo de palma comercial e óleo de camélia foram usados como substratos, e a concentração de OPO foi aumentada para 53,3\% após a cristalização fracionada do produto da reação.

Djajasoepena et al., (2015) tiveram como objetivo sintetizar 1,3-dioleoil-2-palmitoilglicerol (OPO) e determinar a melhor composição de OPO, óleo de coco virgem (VCO), óleo de soja e óleo de peixe para a produção de HMFS para fórmula infantil. A interesterificação de tripalmitina e oleato de etila usando lipase imobilizada de Rhizomucor miehei (Lipozym RM IM) foi usada para sintetizar a OPO. A partir desta pesquisa, foram obtidos HMFS contendo PA até $28,89 \%$, onde $84,49 \%$ está localizado em sn-2, enquanto a posição sn-1,3 é dominada por ácido oleico em até 55,11\% do total de 38,7\% e 70: 18: 10: $2 \mathrm{w} /$ w é a melhor composição de produto de interesterificação, VCO, óleo de soja e óleo de peixe respectivamente, para obter HMFS semelhante ao HMF.

Zou et al., 2016 fizeram a interesterificação catalisada por Lipozyme RM IM da mistura de banha de porco com óleos selecionados em um reator de leito fixo. Quatro misturas de óleos com alta similaridade em perfis de ácidos graxos da gordura do leite humano foram obtidas. A proporção ótima foi determinada como banha: óleo de girassol: óleo de canola: óleo de palmiste: óleo de palma: óleo de algas: óleo microbiano = 1,00: 0,10: 0,50: 0,13: 0,12: 0,02: 0,02. Sob estas condições o produto final apresentou perfis de fusão e cristalização semelhantes aos do da gordura do leite humano. Porém, devido à perda de tocoferóis durante o processo de desacidificação, a estabilidade oxidativa foi inferior à da mistura de óleo.

Os outros três trabalhos encontrados de forma específica no Portal Capes, realizaram pesquisa sobre metodologias e análise dos produto pós interesterificação (Bryś et al., 2019; Wang et al., 2019; Bryś et al., 2017).

Wang et al., (2019), produziram OPO através de três diferentes tecnologias de processamento. A matéria-prima para o primeiro método e o segundo método foi o óleo de palma, e seu catalisador foi Novozym 435 e Lipozyme TL IM. O terceiro método produziu palma estearina (PS) enriquecida em PA catalisando primeiro estearina de palma com metóxido de sódio, e depois estearina de palma enriquecida em PA e misturada óleos vegetais catalisados por Lipozyme TL IM. O conteúdo de OPO e A posição sn-2 PA dos três métodos foi superior a 40,34\% e 39,34\%. O conteúdo relativo de PA localizado na posição sn-2 e OA localizado na posição sn-1, 3 foi superior a $59,97 \%$ e $66,01 \%$.

Bryś et al., (2017) fizeram a avaliação analítica de substitutos da gordura do leite humano sintetizados via interesterificação enzimática de misturas de banha e óleo de cardo de leite por uma lipase específica sn-1,3 comercial imobilizada, utilizando métodos calorimétricos e cromatográficos. Em geral, o teor de FFA da mistura aumentou após a reação de interesterificação. A distribuição posicional dos ácidos graxos no TAG das misturas interesterificadas foi semelhante à gordura do leite humano. As posições sn-1,3 contêm predominantemente AF insaturado, principalmente ácido oleico e a posição sn-2 contém principalmente ácido palmítico.

Alguns trabalhos apresentam o termo acidólise enzimática como o processo abordado (He et al., 2017; Zheng et al., 2017; Cai et al., 2015;) que não deixa de ser uma Interesterificação, ou seja deve-se considerar esses trabalhos como fonte para revisão bibliográfica para estudos da produção de um HFMS.

He et al., (2018), implementaram um método para produzir HFMS usando óleos de microalgas de N. oculata e I. galbana via acidólise sem solvente com as enzimas Novozym 435, Lipozyme 435 e TL-IM e RM-IM como biocatalisadores. Os autores destacaram ainda que HFMS contendo conteúdo relativamente alto de PA na posição sn -2 da estrutura do glicerol e quatro tipos de ácidos graxos n-3 (ALA-SDA-EPA-DHA) podem ser usados como ingredientes importantes em fórmulas infantis. Acreditase que os óleos de microalgas de alto valor têm o potencial de serem aplicados na produção de HFMS para fornecer ácidos graxos benéficos à saúde para o crescimento e desenvolvimento infantil.

Muitos trabalhos que não apresentaram os dois termos principais buscados, também servem como base de referência para o estudo da produção de HFMS, pois fazem a avaliação das variáveis que interferem no processo de interesterificação 
enzimática, como monitoramento do reator e teste de estabilidade dos produtos e de eficiência das enzimas por exemplo (De Paula et al., 2018; Cai et al., 2015; Kotani et al., 2015; Zhao et al., 2019; Wang et al., 2016).

De Paula et al., (2018) por exemplo, avaliaram a eficiência do reator de leito fixo (PBR) através da interesterificação de gordura do leite com óleo de soja, em meios isentos de solventes, catalisada por uma preparação de lipase a partir de $R$. oryzae imobilizado em um suporte híbrido orgânico-inorgânico de álcool polisiloxano-polivinílico (SiO -PVA) funcionando em modo contínuo. $\mathrm{O}$ uso de biocatalisadores em processos em escala laboratorial tem sido realizado em diferentes configurações de reatores, mas o processo contínuo é mais vantajoso em comparação com o lote. Um processo contínuo normalmente emprega um reator de leito fixo, que foi a configuração escolhida para ser estudada aqui. Os resultados obtidos foram satisfatórios e mostraram o potencial deste biocatalisador para a interesterificação enzimática da gordura do leite.

Wang et al., (2015) estabeleceram um método para a síntese de OPO de lipídios estruturados de alta pureza e analisaram de forma comparativa Lipozyme RM IM e Lipozyme TL IM em sistemas sem solvente e sem solvente em aspectos como temperatura, carga enzimática, razão molar do substrato e teor de água. A reutilização de lipases também foram estudados. Os melhores resultados foram obtidos com 10\% de (peso total) Lipozyme TL IM usado em n- hexano com uma razão molar de substrato de 1: 8 a $50^{\circ} \mathrm{C}$. Após $4 \mathrm{~h}$ de reação, havia 92,92\% de PA na posição sn-2 e 56,32\% OA na posição sn-1,3 no produto OPO. Analisados por HPLC-ELSD, os resultados mostraram que o teor de OPO foi de 32,34\% e PPP de 8,14\%. Ênfase especial foi dada para testar a reusabilidade das duas lipases imobilizadas, os resultados mostraram que Lipozyme TL IM era quase não reutilizável, enquanto Lipozyme RM IM conseguia manter sua atividade por pelo menos 15 vezes (cerca de $60 \mathrm{~h}$ ).

Após a busca e seleção dos artigos de interesse, percebeu-se que a busca realizada com os termos interesterificação enzimática e leite humano não especificou a biomolécula de interesse, no caso a gordura do leite humano, por esse motivo muitos trabalhos abordavam algum processo enzimático para oligossacarídeos de leite humano que não era foco para esse estudo.

Neste sentido, realizou-se a busca de mais um termo, no Portal Capes, de forma conjuta para delimitar a biomolécula de intresse e ter mais êxito em trabalhos específicos, o termo utilizado foi lipídeo estruturado. O total de artigos encontrados entre 2015 e 2021 foi de 46 (quarenta e seis). Após esse refinamento pode-se notar que os trabalhos estavam mais de acordo com o que se buscava contudo não foram diferentes dos que já estavam selecionados na primeira busca, apenas facilitou o encontro dos artigos de interesse.

\section{Conclusão}

A gordura do leite humano é a principal fonte de energia para o neonato e possui especificidades em sua composição que contribuem para melhor nutrição e digestão do bebê. Muitas pesquisas são realizadas para tentar produzir um sucedâneo dessa gordura para compor fórmulas infantis e o processo de interesterificação enzimática se mostrou bastante eficaz.

Através da busca de referências pode-se notar que vários grupos de pesquisadores no mundo trabalham com testes de aprimoramento e ajuste da técnica de interesterificação e do uso da melhor enzima para a produção do sucedâneo a partir de diversas fontes naturais de óleos e gorduras. Porém ainda não há muitos registros de produtos patenteados. Dessa maneira fazse necessário que mais pesquisas sejam desenvolvidas para que se chegue em um produto sucedâneo com as melhores característcas para que seja submetido a patente.

Pesquisas acerca da interesterificação entre TAGs de óleo de soja e banha de porco, por exemplo, são recomendadas pois apresentam grande potencial como um sucedâneo da gordura doleite humano patenteável para compor fórmulas infantís.

\section{Referências}

Akoh, C. C. \& Kim, B. H. (2008). Structured lipids. In: C. C. Akoh, D. B. Min, editors. Food lipids-Chemistry, nutrition, and biotechnology. (3a ed.), Boca Raton: CRC Press. 841-864. 
Brys, J., Flores, L. F. V., Gorska, A., Wirkowska-Wojdyla, M., Ostrowska-Ligeza, E. \& Brys, A. (2017). Use of GC and PDSC methods to characterize human milk fat substitutes obtained from lard and milk thistle oil mixtures. Journal of Thermal Analysis and Calorimetry, $130(1), 319$.

Brys, J., 1 Flores, 1. F. V., Górska, A., Ostrowska-Ligwza, E., Brys, A., Niemiec, T. \& Koczon, P. (2019). The Synthesis Followed by Spectral and Calorimetric Evaluation of Stability of Human Milk Fat Substitutes Obtained from Thistle Milk and Lard. International Journal of Analytical Chemistry.

Cai, H., Yang, L., Zhao, M., Fu, G., Lai, J. \& Feng, F. (2015) Immobilization, Regiospecificity Characterization and Application of Aspergillus oryzae Lipase in the Enzymatic Synthesis of the Structured Lipid 1,3-Dioleoyl-2-Palmitoylglycerol. PLoS One, 10(7).

Costa, A.G. V. \& Sabarense, C. M. (2010). Modulação e composição de ácidos graxos do leite humano. Rev. Nutr., Campinas, 23(3), $445-457$.

De Paula, A.V. Nunes, G.F.M., De Castro, H. F. \& Santos, J. C. Dos. (2018). Performance of packed bed reactor on the enzymatic interesterification of milk fat with soybean oil to yield structure lipids. International Dairy Journal, 86. 1-8.

Djajasoepena, S., Suprijana, O., Saadah, D. R., Pratomo, U. \& Puspitasari, S. (2015). Production of human milk Fat Replacement Rich of 1,3-dioleoyl-2palmitoilglycerol From Enzymatic Interesterification Tripalmitin, Ethyl Oleate And Mixture of VCO, Soybean Oil And Fish Oil. Procedia chemistry, 16, 384391.

Forsyth, S., Gautier, S., \& Salem, N. (2017). A importância do DHA e ARA dietéticos no início da vida: Uma perspectiva de saúde pública. Proceedings of the Nutrition Society, 76.(4), 568-573.

Ghosh, M., Sengupta, A., Bhattacharyya, DK et al. (2016). Preparação de análogo da gordura do leite humano por reação de interesterificação enzimática utilizando estearina de palma e óleo de peixe. J Food Sci Technol, 53, 2017-2024.

He, Y., Qiu, C., Guo, Z., Huang, J., Wang, M. \& Chen, B. (2017). Production of new human milk fat substitutes by enzymatic acidolysis of microalgae oils from Nannochloropsis oculata and Isochrysis galbana. Bioresource technology, 238,129-138.

He, Y., Li J., Guo, Z. \& Chen, B. (2018). Synthesis of novel medium--long-medium type structured lipids from microalgae oil via two-step enzymatic reactions Process Biochem, 68, 108.

Kim, B.\& Akoh, C. (2015). Recent Research Trends on the Enzymatic Synthesis of Structured Lipids. Journal Of Food Science, 80(8), C1713-C1724.

Korma, S.A., Zou, X., Ali A.H., Abed, S.M., Jin, Q. \& Wang, X. (2018). Preparation of structured lipids enriched with medium- and long-chain triacylglycerols by enzymatic interesterification for infant formula. Food and Bioproducts Processing, 107,121-130.

Kotani, K., Yamamoto, Y. \& Hara, S.K. (2015). Enzymatic Preparation of Human Milk Fat Substitutes and Their Oxidation Stability. Journal of Oleo Science, 64(3), 275 .

Kus, M. M. M., Silva, S. A. da, Aued-Pimentel S. \& Mancini-Filho, J. (2011). Nutrition facts of infant formulas sold in São Paulo state: assessment of fat and fatty acid contents. Rev. Nutr., Campinas, 24(2), 209-218.

Lee, N., Oh, S., Kwon, D. \& Yoon, S. (2015). Production of 1, 3-dioleoyl-2-palmitoyl glycerol as a human milk fat substitute using enzymatic interesterification of natural fats and oils. Food Science and Biotechnology, 24(2), 433-437.

Nejrup, R. G. \& Licht, T. R. (2017). Hellgren L.I. Fatty acid composition and phospholipid types used in infant formulas modifies the establishment of human gut bacteria in germ-free mice. Sci Rep. 7.

Pereira, A.S. et al. (2018). Metodologia da pesquisa científica. UFSM. https://repositorio.ufsm.br/bitstream/handle/1/15824/Lic_Computacao_MetodologiaPesquisa-Cientifica.pdf? sequence $=1$.

Silva, R. C. da \& Gioielli, L. A. (2009). Lipídios estruturados: alternativa para a produção de sucedâneos da gordura do leite humano. Quim. Nova, 32 (5), $1253-1261$

Silva, R. C. da \& Gioielli, L. A. (2006). Propriedades físicas de lipídios estruturados obtidos a partir de banha e óleo de soja. Brazilian Journal of Pharmaceutical Sciences. 42(2).

Silva, R. C., Soares, F. A. S.de M., Hazzan, M., Capacla, I. R., Gonçalves, M. I. A. \& Gioielli, L. A. (2012). Continuous enzymatic interesterification of lard and soybean oil blend: Effects of different flow rates on physical properties and acyl migration. Journal of Molecular Catalysis B: Enzymatic, 76, 23-28.

Soumanou, M. M., Périgon, M. \& Villeneuve, E. P. (2013). Lipase-catalyzed interesterification reactions for human milk fat substitutes production: A review. European Journal of Lipid Science and Technology, 15, 270-285.

Tecelão, C., Perrier, V., Dubreucq, E. \& Ferreira-Dias, S. (2019). Production of Human Milk Fat Substitutes by Interesterification of Tripalmitin with Ethyl Oleate Catalyzed by Candida parapsilosis Lipase/Acyltransferase. Journal of the American Oil Chemists' Society, 96 (7), $777-787$.

Zhao, J. F., Lin, J. P., Yang, L. R. \& Wu, M. B. (2019). Enhanced Performance of Rhizopus oryzae Lipase by Reasonable Immobilization on Magnetic Nanoparticles and Its Application in Synthesis 1,3-Diacyglycerol. Applied Biochemistry and Biotechnology, 188 (3), $677-689$.

Wang, J., Liu X., Wang, XD, Dong, T., Zhao, Xing-Yu, Zhu, D., Mei, Yi-Yuan, \& Wu, Guo-Hua. (2016). Selective synthesis of human milk fat-style structured triglycerides from microalgal oil in a microfluidic reactor packed with immobilized lipase. Bioresource Technology, $220,132-141$.

Wang, Z., Du, W., Dai, L. \& Liu, D. (2016). Study on lipozyme TL IM-catalyzed esterification of oleic acid and glycerol for 1,3-diolein preparation. J MolCatal, B Enzym.127,11-17.

Wang, Z., Liu, L., Liu, L., Liu, T., Li, C. \& Sun, L. (2019). 1,3-Dioleoyl-2-palmitoylglycerol-rich triacylglycerol characterization by three processing methods. International Journal of Food Properties, 22(1),1156-1171. 
Research, Society and Development, v. 10, n. 3, e36210313469, 2021

(CC BY 4.0) | ISSN 2525-3409 | DOI: http://dx.doi.org/10.33448/rsd-v10i3.13469

Wei, W., Jin, Q. \& Wang, X. (2019). Human milk fat substitutes: Past achievements and current trends Progress. Lipid Research, 74, 69-86.

Wei, W., Fengy, Y., Zhang, X., Cao, X. \& Feng, F. (2015). Synthesis of structured lipid 1,3-dioleoyl-2-palmitoylglycerol in both solvent and solvent-free system. LWT - Food Science and Technology. 60(2), 1187-1194.

Yuan, T., Wei, W., Wang, X. \& Jin, Q. (2020). Biosynthesis of structured lipids enriched with medium and long-chain triacylglycerols for human milk fat substitute. Lebensmittel-Wissenschaft + [ie und] Technologie.128.

Yuan, T., Zhang, H., Wang, X., Yu, R., Zhou, Q., Wei, W., Wang, X. \& Jin, Q. Triacylglycerol containing medium-chain fatty acid s (MCFA-TAG): The gap between human milk and infant formulas. International Dairy Journal. 99.

Zheng, M., Wang, S., Xiang, X., Shi, J., Huang, J., Deng, Q., Huang, F. \& Xiao, J. (2017). Facile preparation of magnetic carbon nanotubes-immobilized lipase for highly efficient synthesis of 1,3-dioleoyl-2-palmitoylglycerol-rich human milk fat substitutes. Food chemistry, 228,.476-483.

Zou, X., Jin, Q., Guo, Z., Xu, X. \& Wang, X. (2016). Preparation and Characterization of Human Milk Fat Substitutes Based on Triacylglycerol Profiles Journal of the American Oil Chemists' Society, 93(6), 781-792. 